\title{
Management Strategies for Femoral Head Replacement Arthroplasty in Uremia Patients: Case Report
}

\author{
Yu Xie ${ }^{1}$, Xu Biao Ma ${ }^{1}$, Lun Li Xie ${ }^{1}$, Jian Li ${ }^{2}$, Jun Zhu ${ }^{1}$, Jun Yang ${ }^{2}$, Ming Biao Huang, Fa Qin ${ }^{1}$ and Dan Pu*1 \\ ${ }^{1}$ Department of Minimally Invasive orthopedic, China
}

${ }^{2}$ Department of Traumatic Orthopedics, Rehabilitation Medicine Center, China

Received: April 19, 2018; Published: April 27, 2018

*Corresponding author: Dan Pu, MSMed, Department of Orthopedics, The First People's Hospital of Huaihua, Jishou University School of Medicine, China

\begin{abstract}
To report the case of a patient with uremia who presented left femoral neck fractures due to osteoporosis caused by renal osteodystrophy. The special patient such as uremia with femoral neck fracture need a criterion for perioperative management and type of surgery.

Keywords: Hip replacement; Uremia; Osteoporosis

Abbreviations: THA: Total Hip Arthroplasty; HHA: Hemiarthroplasty; TSFFN: Trans-Cervical or Sub-Capital Fractures of Femoral Neck; BMD: Bone Mineral Density; LCP: Locking Compression Plates; DCD: Dynamic Collo-Diaphyseal Plate; DHS: Dynamic Hip Screw; PMMA: Polymethylmethacrylate
\end{abstract}

\section{Introduction}

It is feasible to accept the total hip arthroplasty (THA) or hemiarthroplasty (HHA) for the femoral neck fracture patient [1]. Indeed, this therapeutic method has been also used for the particular patient with the sickle cell, Jehovah's witness patients $[2,3]$. However, there are differences of management of perioperative period for uremia compared the above diseases in femoral neck fracture patient [4]. The purpose of this study was to report on 1 uremia patient who accepted the femoral head replacement due to min-trauma causing the left femoral neck fracture. Especially, to describe the Multidisciplinary management of perioperative period and clinical outcomes.

\section{Case Report}

\section{History and Examination}

This patient was a 51-year old woman (weight $50 \mathrm{~kg}$, height $155 \mathrm{~cm}$ ) who had left femoral neck fracture with uremia (Figures 1 \& 2 ). She has been accepted the regular hemodialysis since diagnosed uremia. There were history of autologous arteriovenous fistulization of left radial artery and vein and nephrogenic osteoporosis. There was no history of allergy to medications or of any previous anesthesia-related problems. Results of cardiopulmonary function were within normal limits. Results of laboratory investigations were within normal limits, with a hemoglobin value of $119 \mathrm{~g} / \mathrm{L}$, except of the renal function. The CT scans of left hip joint revealed the trans-cervical or sub-capital fractures of femoral neck (TSFFN) and dual energy $\mathrm{x}$-ray proved the low grade bone mineral density (BMD).

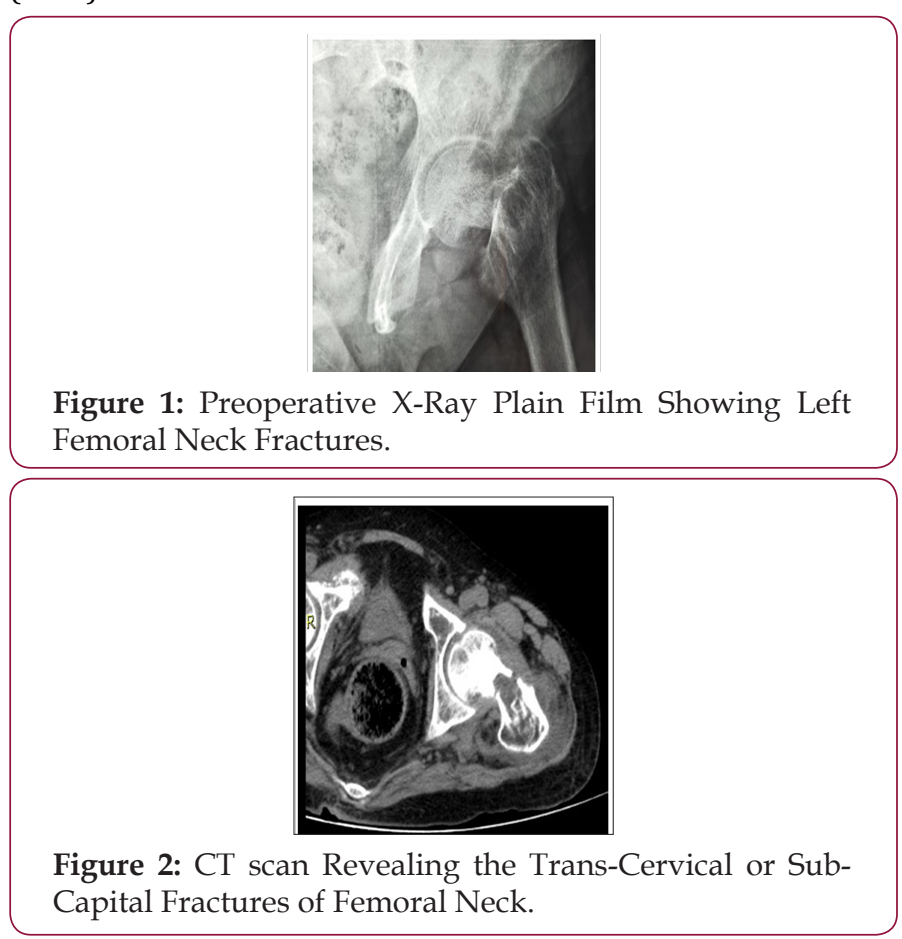




\section{Management of Perioperative Period}

Reference to the ERAS for the THA and HHA with the optimal results $[5,6]$, the management strategies for this patient included following items like multidisciplinary consultation and team work, suitable fluid management, effective antibiotics and prophylactic anti-coagulation, reduction renal anemia, regular hemodialysis, suitable analgesia, and early rehabilitation. Indeed, the minor adjustments were performed dependent on the results of routine examinations. Notably, the multidisciplinary consultation and team work consisted of the Department of Nephrology, Department of Hematology, Intensive care unit, Pharmacy Department, Anesthetist, Nurse, and Rehabilitative Physician. The work details of the above specialists were revealed by the following Table 1 . The KocherLangenbeck approach was use for left hip hemiarthroplasty about 6th days. The regular examinations and appropriate adjustment were performed depending on the test results.

Table 1: Hip Arthroplasty Multidisciplinary Diagnosis and Treatment Recommendations.

\begin{tabular}{|c|c|c|}
\hline Items & Summary and Recommendation & $\begin{array}{l}\text { Responsible Team } \\
\text { Member }\end{array}$ \\
\hline Preadmission counseling & $\begin{array}{l}\text { The oral or written information which are use to describe the expect } \\
\text { and recovery for patient. }\end{array}$ & $\begin{array}{l}\text { Resident doctor and } \\
\text { Surgeon }\end{array}$ \\
\hline Hospitalizing education & $\begin{array}{c}\text { The suitable high protein diet and eternal nutrition approval, } \\
\text { professional nursing steps. }\end{array}$ & Nurses \\
\hline Antithrombotic prophylaxis & $\begin{array}{c}\text { The application of low molecular weight heparin per day and functional } \\
\text { training for uninjured limb. }\end{array}$ & Nurses \\
\hline Preoperative fasting \& carbohydrate loading & $\begin{array}{l}\text { The perioperative period is } 6 \mathrm{hrs} \text { for liquids and } 8 \mathrm{hrs} \text { for solid food. The } \\
\text { low salt, fat and high protein diet is suggested. }\end{array}$ & Resident doctor and Nurses \\
\hline Preoperative preparation & $\begin{array}{l}\text { The multidisciplinary consultations include hematology, pharmacy, } \\
\text { anesthesiology, nephrology department and ICU. }\end{array}$ & Specialists \\
\hline Preoperative management of Uremia & $\begin{array}{l}\text { The regular hematodialysis ( } 3 \text { times per week) is suggested, and the no- } \\
\text { heparin dialysis is performed on the day before surgery. }\end{array}$ & Specialists \\
\hline Antimicrobial prophylaxis \& skin preparation & $\begin{array}{l}\text { The application of routine prophylaxis with first-generation } \\
\text { cephalosporin } 30 \text { minutes before incision. The Betadine is suggested for } \\
\text { skin preparation. }\end{array}$ & Surgeon \\
\hline Anesthesia protocol & $\begin{array}{l}\text { The standard endotracheal anesthesia is suggested due to fluid } \\
\text { management and coping with stress for patient. }\end{array}$ & Anesthetist \\
\hline Surgical technique & The standard clinical pathway and antibiotic bone cement is suggested. & Surgeon \\
\hline Surgical drainage & $\begin{array}{c}\text { The routine surgical site drains is also recommendation. } \\
\text { The concentrated red blood cell and fresh frozen plasma are suggested } \\
\text { based on the bleeding volume. }\end{array}$ & Surgeon \\
\hline Fluid management & $\begin{array}{l}\text { The fluid management based on the heart rate and the results of } \\
\text { laboratory investigations especially of the electrolyte }\end{array}$ & Anesthetist \\
\hline Urinary drainage & Drawing the urinary drainage as soon as possible. & Nurses \\
\hline Postoperative analgesia & $\begin{array}{l}\text { The general anaesthetic medication are suggested, the postoperative } \\
\text { analgesia program are performed regulation dependent on the Visual } \\
\text { Analogue Scale (VAS). }\end{array}$ & Anesthetist and Surgeon \\
\hline Postoperative antithrombotic prophylaxis & $\begin{array}{l}\text { The application of low molecular weight heparin per day and functional } \\
\text { training for limb as soon as possible, and the program is adjusted based } \\
\text { on the results of coagulation function, blood routine. }\end{array}$ & Surgeon \\
\hline Postoperative management of Uremia & $\begin{array}{c}\text { The no-heparin dialysis is performed after completing surgery. } \\
\text { The regular hematodialysis (three times per week) is performed for } \\
\text { postoperative duration. }\end{array}$ & Specialists \\
\hline Anemia reduction & The concentrated red blood cell and fresh frozen plasma are suggested. & Surgeon \\
\hline Postoperative nutrition & $\begin{array}{l}\text { Patient is encouraged to have oral intake at will, avoiding high salt and } \\
\text { fat food. The suitable high protein diet is suggested }\end{array}$ & Nurses \\
\hline Postoperative rehabilitation & $\begin{array}{c}\text { The programs of rehabilitation include muscular strength exercise, } \\
\text { range of motion for knee and hip joint. }\end{array}$ & Rehabilitative physician \\
\hline
\end{tabular}

\section{Results of Radiological Examination on the Perioperative} Duration and the Follow-Up Time.

The regular X-ray plain film showed normal prosthetic location, and the fractures around the prosthesis occurred (Figure 3). However, acute pain and malformation of left leg occurred on the postsurgical 6th day. And the radiographic examination showed the left distal femur fracture (Figure 4). After performed the plaster immobilization, the postoperative X-ray observation showed the part of callus formation on the follow up duration of 2 and 4 months (Figures 5 \& 6). 


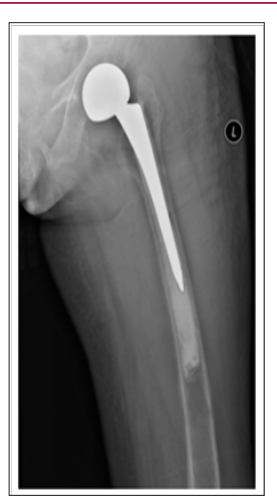

Figure 3: Postoperative X-Ray Plain Film on the First Day.

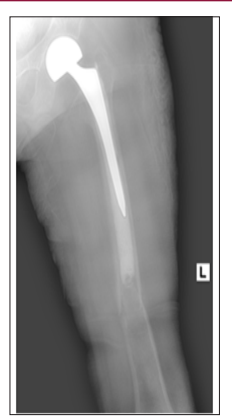

Figure 4: Postoperative X-Ray Plain Film on the $6^{\text {th }}$ Day.

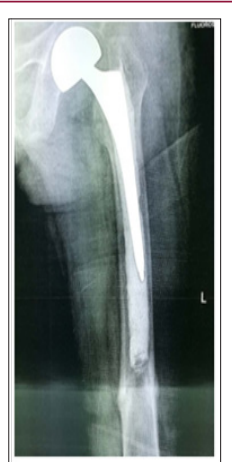

Figure 5: Postoperative X-ray plain film on the 2 months.

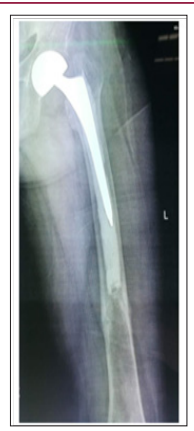

Figure 6: Postoperative X-Ray Plain Film on the 4 Months.

\section{Discussion}

It is a consensus that renal osteodystrophy may cause the osteoporosis. Besides, this is one of the causes of morbidity in uremia patients undergoing hematodialysis treatment for their kidney failure. It is easier to occur femoral neck fracture for this special patient than the aging population with osteoporosis [7]. Indeed, it is still lack of the criterion or consensus for the above patient, even if some researchers emphasized that the therapy approaches in respect to the age, initial trauma, life expectancy, and the femoral head salvage of the patient [8]. The strategy of femoral neck fractures for adult with renal osteodystrophy is controversial. Mataliotakis G et al. [9]. provided special assessment and plan of these adults, after they had been reviewed to the published literatures with respect to the young individuals with renal osteodystrophy caused by uremia [9].

This article revealed some treatment options in such poor bone quality conditions, which encompass cannulated screws and locking compression plates (LCP), Knowles pins, dynamic collo-diaphyseal plate (DCD), Hydroxyapatite coated screws, Dynamic hip screw (DHS), Polymethylmethacrylate (PMMA), and hemiarthroplasty (HA) or total hip arthroplasty (THA). Moreover, there is a debate whether the preoperative BMD assessed by surgeon or not. However, there is a lower limit for the patient with renal osteodystrophy than the population with osteoporosis. Notably, the importance of BMD was emphasized by the authors in this literature. Even if operative treatment of femoral neck fractures is recommended over conservative management, actually, the type of surgery will be decided dependent on fracture region, patients' age and demands, medical condition of the patients, and ambulation status. In this case, the cemented artificial femoral head replacement was performed on basis of the type of fracture, patient's demands and life expectancy [9].

With ten years follow-up duration, Rajan Madhok reported a 24-year-old woman with chronic renal failure whom accepted the bilateral, cemented bipolar hip arthroplasty [10]. It is critical to provide stable medical conditions in perioperative period with a careful team approach of the Multidisciplinary management which can limit short term complications and mortality. In Karapinar's case report, team work with nephrologist and surgeon were emphasized for the adult with chronic renal failure received hip joint replacement due to bilateral femoral neck fractures [11].

Spontaneous prosthetic femoral fracture occurred in this case. The following possible improvements need to perform the research in the future. Firstly, to increase the size and length of femoral components but avoiding to use the bone cement due to the bio-mechanical property. Some authors and coworkers proved the feasibility of no-cemented hip replacement for patients with renal osteodystrophy [12]. Secondly, there is a possibility for usage of the limb distraction to decrease the risk of fracture on the perioperative duration. In fact, more researches need to be performed to investigate systematic treatment process.

\section{Conclusion}

Many limits of this case cannot be ignored. In the future, ERAS and perioperative management for special individual such as uremia patient need to investigate. It is of great importance, especially, to perform the feasibility for the patient with osteoporosis caused by the renal osteodystrophy. 


\section{References}

1. Petis S, Howard JL, Lanting BL, Vasarhelyi EM (2015) surgical approach in primary total hip arthroplasty: anatomy, technique and clinical outcomes. Can J Surg 58(2): 128-139.

2. Jauregui JJ, Kapadia BH, Banerjee S, Issa K, Su S (2014) Blood management strategies for total hip arthroplasty in Jehovah's witness patients. Surg Technol Int 24: 338-343.

3. Patel YD, Szczech BW, Patel S, Issa K, Kapadia BH, et al. (2014) Management strategies for total hip arthroplasty in sickle cell patients. J Long Term Eff Med Implants 24(2-3): 219-224.

4. Freitas A, Neto SLDM, Loures FB, Leonardo C, Maurício S, et al. (2016) Simultaneous bilateral femoral neck fracture in a patient with renal osteodystrophy. Trauma Case Reports 3: 26-31.

5. Stowers MD, Manuopangai L, Hill AG, Gray JR, Coleman B, et al. (2016) Enhanced Recovery after Surgery in elective hip and knee arthroplasty reduces length of hospital stay. ANZ J Surg 86(6): 475-479.

6. Zhu S, Qian W, Jiang C, Canhua Ye, Xi Chen, et al. (2017) Enhanced recovery after surgery for hip and knee arthroplasty: a systematic review and meta-analysis. Postgrad Med J 93(1106): 736-742.
7. Ureña P, Bernard-Poenaru O, Ostertag A, Baudoin C, Cohen-Solal M, et al. (2003)Bone mineral density, biochemical markers and skeletal fractures in haemodialysis patients. Nephrol Dial Transplant 18(11): 2325-2331.

8. Chadha M, Balain B, Maini L, Dhal A (2001) Spontaneous bilateral displaced femoral neck fractures in nutritional osteomalacia-a case report. Acta Orthop Scand 72: 94-96.

9. Mataliotakis G, Lykissas MG, Mavrodontidis AN, Kontogeorgakos VA, Beris AE (2008) Femoral neck fractures secondary to renal osteodystrophy. Literature review and treatment algorithm. Journal of musculoskeletal \& neuronal interactions 9(3): 130-137.

10. Rajan Madhok, James Rand A (1993) Ten-year Follow-up study of missed, simultaneous, bilateral, femoral-neck fractures treated by bipolar arthroplasties in a patients with chronic renal failure. Clinical orthopaedics and related research 291: 185-187.

11. Karapinar H, Ozdemir M, Akyol S, Ulkü O (2003) Spontaneous bilateral femoral neck fractures in a young adult with chronic renal failure. Acta OrthopaedicaBelgica 69(1): 82-85.

12. Anderson Freitas, Silvio Leitede, Macedo Neto, Leonardo C A B, Maurício Siqueira C, et al. (2003) Simultaneous bilateral femoral neck fracture in a patient with renal osteodystrophy. Trauma Case eports 3: 26-31.

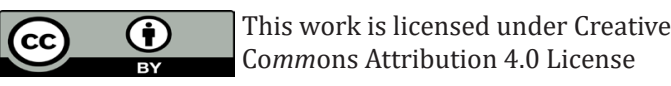

Submission Link: https://biomedres.us/submit-manuscript.php

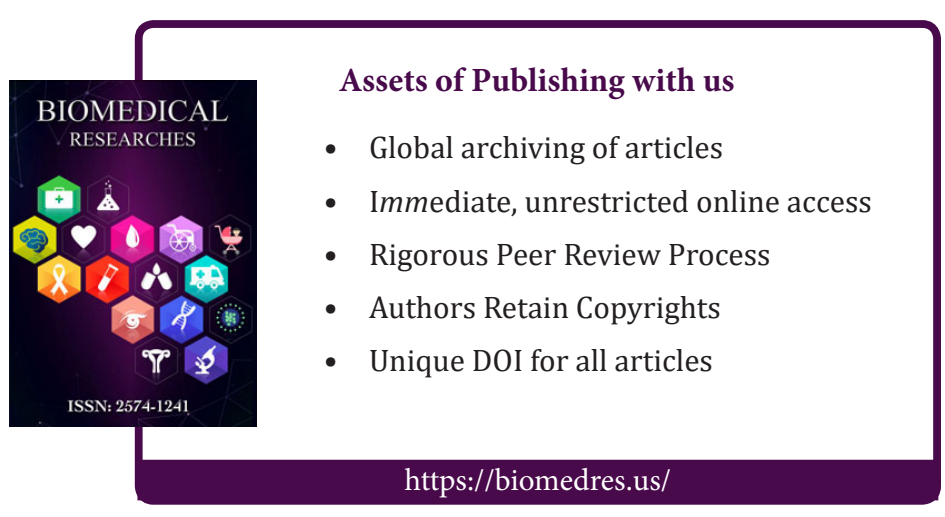

